\title{
The Architecture of Innovation
}

\section{Citation}

Lawrence Lessig, The Architecture of Innovation, 51 Duke L. J. 1783 (2002).

\section{Published Version}

http://scholarship.law.duke.edu/dlj/vol51/iss6/2/

\section{Permanent link}

http://nrs.harvard.edu/urn-3:HUL.InstRepos:12911353

\section{Terms of Use}

This article was downloaded from Harvard University's DASH repository, and is made available under the terms and conditions applicable to Other Posted Material, as set forth at http:// nrs.harvard.edu/urn-3:HUL.InstRepos:dash.current.terms-of-use\#LAA

\section{Share Your Story}

The Harvard community has made this article openly available.

Please share how this access benefits you. Submit a story.

\section{Accessibility}




\title{
Lecture
}

\section{THE ARCHITECTURE OF INNOVATION}

\author{
LAWRENCE LESSIG $\dagger$
}

Every society has resources that are free and resources that are controlled. A free resource is one that anyone equally can take; a controlled resource one can take only with the permission of someone else. $E=M C^{2}$ is a free resource. You can take it and use it without the permission of the Einstein estate. 112 Mercer Street, Princeton, is a controlled resource. To sleep at 112 Mercer Street requires the permission of the Institute for Advanced Study.

A time is marked not so much by the ideas that are argued about, but by the ideas that are taken for granted. The character of an era hangs on what one need not question; the power in a particular moment runs with the notions that only the crazy would draw into doubt.

Sometimes that is just fine. I'm happy the question of infanticide is off the table; how extraordinarily tedious it would be if we regularly had to debate whether we wanted to be a democracy. In the language of computer programming, it is a great and valuable thing that certain ideals get compiled into social life. It is an advantage that everything need not at every moment be interpreted.

But sometimes a society gets stuck because of an idea it can't quite question, or dislodge. Sometimes the idea "sticks" the society. And when that happens, the hardest part of political action-the hardest part of changing an aspect of society-is to get people to see

Copyright () 2002 by Lawrence Lessig.

$\dagger$ Professor of Law, Stanford Law School. This lecture was delivered as the inaugural Meredith and Kip Frey Lecture in Intellectual Property at Duke University School of Law on March 23, 2001. 
how this taken-for-granted idea might be wrong. To get people to believe that there might be something contestable about what seemed unquestionable, or even to get them to see that the story is more complex than they believed.

And so it is with us.

We live in an era when the idea of property is just such a thought, or better, just such a non-thought; when the importance and value of property is taken for granted; when it is impossible, or at least for us, very hard, to get anyone to entertain a view where property is not central; when to question the universality and inevitability of complete propertization is to mark yourself as an outsider. As an alien.

I don't mean the debate about commodification crystallized by feminism, or a debate about whether we conceive of social relations as a kind of property right. That is a fundamentally contested discourse, rich with possibility and profoundly important.

I mean something much more mundane and simple. I mean the question of property in resources. Or, more precisely, the question of whether resources should be controlled-or how they should be controlled.

For about this question, there is apparently no debate. As Yale Professor Carol Rose puts it, we live in a time when the view is that "the whole world is best managed when divided among private owners." The most creative minds in public policy turn their attention to how best to divide resources up. The assumption is that well-divided resources will always work best.

We have this view-this taken-for-granted, background viewbecause for the last hundred years, we've debated a related question, and that debate has come to an end. For the last hundred years, the question exciting political philosophy has been which system of control works best. Should resources be controlled by the state, or controlled by the market? And this question, we all rightly believe, has been answered. In all but a few cases, for a wide range of reasons, we know this: that the market is a better tool for controlling resources than the state. That between the two, there is no real debate.

1. Carol Rose, The Comedy of the Commons: Custom, Commerce, and Inherently Public Property, 53 U. CHI. L. REV. 711, 712 (1986). 
But this confidence obscures a distinct and more basic question. This certainty about the superiority of the market to the state leads us to ignore an issue that comes before. Not the question of which system of control is best for any given resource, but instead the question-should a resource be subject to control at all. Not the market versus the state, but controlled versus free.

If communism versus capitalism was the struggle of the twentieth century, then control versus freedom will be the debate of the twentyfirst century. If our question then was how best to control, our question now will become whether to control. What would a free resource give us that controlled resources do not? What is the value in avoiding systems of control?

Now, this is a hard question to ask at Duke. It's actually a hard question to ask anywhere, as it usually elicits a sheeplike stare among most in the audience. But it is particularly hard to ask here because here it's been asked, and answered, many times before.

The controlled versus free debate gets reborn within law in an essay about the public domain, penned by Professor David Lange. ${ }^{2}$ The paradox between the controlled and the free is crystallized in the first great book of the information era, by one who has romantically denied the romance in authorship, Professor James Boyle. ${ }^{3}$ And the struggle to preserve internationally the space of the free in the core of science and the periphery has at its center the energy of Professor Jerome Reichman. ${ }^{4}$

And so here is the real struggle of one invited to Duke to speak of things learned from Duke: The exercise quickly feels less like a lecture, and more like an exam. At each moment I feel myself pulled to look up for correction or scoring; I sit spinning at my desk wondering whether there is anything new to say to a school that reminds us

2. David Lange, Recognizing the Public Domain, 44 LAW \& CONTEMP. Probs. 147 (Autumn 1981).

3. James Boyle, Shamans, Software, And Spleens: LaW AND the Construction OF THE INFORMATION SOCIETY (1996).

4. J.H. Reichman, Of Green Tulips and Legal Kudzu: Repackaging Rights in Subpatentable Innovations, 53 VAND. L. REV. 1743 (2000) [hereinafter Reichman, Of Green Tulips]; J.H. Reichman \& Paul F. Uhlir, Database Protection at a Crossroads: Recent Development and Their Impact on Science and Technology, 14 BERKELEY TECH. L.J. 793 (1999); Pamela Samuelson, Randall Davis, Mitchell D. Kapor \& J.H. Reichman, A Manifesto Concerning the Legal Protection of Computer Programs, 94 COLUM. L. REV. 2308 (1994). 
about how much of the old there is in everything new. And then, for a moment, I'm relieved by the thought that if I say nothing new, then you all will feel at least vindicated in your view of how little new there is in the work of any author, or at least this author.

But here's the way I want to take your arguments, and say something new. Put most abstractly, I want to translate your arguments into space; to place them within an architecture. And then to demonstrate the points you've already made through the machines we've come to know. Through the machines that have defined the potential for a kind of freedom that we, as a culture, have not known for a very long time.

\section{COMMUNICATION SYSTEMS}

Professor Yochai Benkler of New York University School of Law is a theorist of free communication who says to think about a system of communication divided among three layers. ${ }^{5}$ These layers interconnect; each depends upon the other; any communication depends upon all three. ${ }^{6}$

At the bottom of these three, there is the physical layer-the wires that connect the phones or the computers; the cable across which television might be broadcast; above that, the logical layerthe system that controls who gets access to what, or what gets to run where; and above that, the content layer-the stuff that gets said or written within any given system of communication.

Now, each of these layers in principle could be controlled or free. They would be free if they were organized in a commons-organized so that anyone could get access or equal terms, whether they had to pay (a fixed and neutral charge) or not. They would be controlled if they were the property of someone else-someone who had a right to exclude, or to decide whether to grant access based upon his or her own subjective reasons.

Depending on whether these layers are free, or are controlled, the communications system that gets built differs.

5. Yochai Benkler, From Consumer to Users: Shifting the Deeper Structures of Regulation Toward Sustainable Commons and User Access, 52 FED. COMM. L.J. 561, 562-63 (2000).

6. See Lawrence Lessig, The Future of Ideas: The Fate of the Commons in a CONNECTED WORLD 23-26 (2001) (explaining the application of the layers approach to the Internet). 
Consider four possibilities as we vary whether each of these layers is owned or free.

Speakers' Corner. Orators and loons gather every Sunday in Hyde Park's Speakers' Corner to rage about something or nothing at all. It has become a London tradition. It is a communication system organized in a specific way. The physical layer of this communication system (the park) is a commons; the logical layer (the language used) is also a commons. And the content layer (what these nuts say) is their own creation. It too is unowned. All three layers in this context are free; no one can exercise control over the kinds of communications that might happen here.

Madison Square Garden. Madison Square Garden is another place where people give speeches. But Madison Square Garden is owned. Only those who pay get to use the auditorium; and the Garden is not obligated to take all comers. The physical layer is therefore controlled. But like Speakers' Corner, both the logical layer of the language and the content that gets uttered is not controlled in the context of the Garden. They too remain free.

The Telephone System. Before the breakup, the telephone system was a single-unitary system. The physical infrastructure of this system was owned by AT\&T; so too was the logical infrastructure, which determined how and to whom you could connect. But what you said on an AT\&T phone (within limits at least) was free: The content of the telephone conversations was not controlled, even if the physical and logical layer underneath were.

Cable TV. Finally, think of cable TV. Here the physical layer is owned in the form of the wires that run the content into your house. The logical layer is owned-only the cable companies get to decide what runs into your house. And the content layer is owned-the shows that get broadcast are copyrighted shows. All three layers are within the control of the cable TV company; no communications layer, in Professor Benkler's sense, remains free.

This then is the range. A communications system, and hence, a system for innovation, could be any of the four, or, of course, more than these four. But these four set the range that will best help us understand a very specific example: The Internet. 
It is commonplace to think about the Internet as a kind of commons. It is less commonplace to actually have an idea what a commons is. ${ }^{7}$

By a commons I mean a resource that is free. Not necessarily zero cost, but, if there is a cost, it is a neutrally imposed or equally imposed cost.

Central Park is a commons: ${ }^{8}$ an extraordinary resource of peacefulness in the center of a city that is anything but; an escape and refuge that anyone can take and use without the permission of anyone else.

The public streets are a commons: on no one's schedule but your own, you enter the public streets, and go in any direction you wish. You can turn off of Broadway onto Fifty-second Street at any time, without a certificate or authorization from the government.

Fermat's Last Theorem is a commons: a challenge that anyone could pick up and complete, as Andrew Wiles, after a lifetime of struggle, did.

Open source, or free software, is a commons: the source code of Linux, for example, lies available for anyone to take, to use, to improve, to advance. No permission is necessary; no authorization may be required.

These are commons because they are within the reach of members of the relevant community without the permission of anyone else. They are resources that are protected by a liability rule rather than a property rule. Professor Reichman, for example, has suggested that some innovation be protected by a liability rule rather than a property rule. ${ }^{9}$ The point is not that no control is present, but rather that the kind of control is different from the control we grant to property.

The Internet is a communication system. It too has these three layers. At the bottom, the physical layer, are wires and computers,

7. See generally id. (discussing the idea of the commons in intellectual property theory).

8. I used Central Park, Fermat's Last Theorem, and open source as examples of commons in an Address Before the First Amendment and the Media Symposium at the Fordham University School of Law on February 9, 1999. For the full text of this lecture, see Lawrence Lessig, Commons and Code, 9 FordhAM INTELl. Prop. MEdia \& ENT. L.J. 405 (1999).

9. See generally Reichman, Of Green Tulips, supra note 4 (arguing that protecting small, subpatentable innovations with a liability rule rather than a property rule would yield a net benefit to society). 
and wires linking computers. These resources are owned. The owners have complete control over what they do with their wires or computers, or wires linking computers. Property governs this layer.

On top of the physical layer is a logical layer-the protocols that make the Net run. These protocols are many, all chucked into a single box called TCP/IP. Their essence is a system for exchanging datagrams, but we miss something important about the system if we focus exclusively on the essence.

For at the core of this logical layer is a principle of network design. At the core of the Internet's design is an ideal called "end-toend" (e2e). First articulated by network architects Jerome Saltzer, David Reed, and David Clark, ${ }^{10}$ e2e says to build the network so that intelligence rests in the ends, and the network itself remains simple. Simple networks, smart applications.

The reason for this design was simple. With e2e, innovation on the Internet didn't depend upon the network. New content or new applications could run regardless of whether the network knew about them. New content or new applications would run because the network simply took packets of data and moved them along. The fundamental feature of this network design was neutrality among packets. The network was simple, or "stupid," in David Isenberg's sense, ${ }^{11}$ and the consequence of stupidity, at least among computers, is the inability to discriminate. Innovators thus knew that, if their ideas were wanted, the network would run them; that this network was architected never to allow anyone to decide what would be allowed.

This means that this layer of this network-this feature of the network that distinguished it from all that had been built beforebuilt this network into a commons. One was free to get access to this network and share its resources. The protocols were designed for sharing, not exclusive use. Discrimination, which lies at the heart of a property system, was not possible in e2e. This system was coded to be free. That was its nature.

Thus, on top of a physical layer that is controlled rests a logical layer that is free. And then, on top of this free layer is a content layer that is both free and controlled.

The free part is all of the content that effectively rests in the public domain. The facts, data, abandoned property, undiscovered

10. LESSIG, supra note 6, at 34-35.

11. Id. at 38. David Isenberg was an engineer at Bell Labs. He advocated "stupid" telephone networks, earning him great support on the web, but not from his employers. Id. 
theft-this is the content that is open for the taking and that is taken openly. But it also includes a part dedicated to be open: open source or free software, dedicated to be free.

This free resource does more than entertain, or build culture; this free resource teaches the world about how the Net functions, or is free. For example, every web page both displays and carries its source, so that its source can be copied and modified for different displays.

This free content coexists with content that is controlled. Software that is sold; digital content-music, movies, greeting cards-that is controlled. You can link to mp3.com and listen to music that is free; you can link to amazon.com and read a book that is controlled. The network doesn't care much about what linking occurs. It's neutral among the linking, and the result of this neutrality is a mix.

This, then, is a picture of the complexity we call the Internet. At the bottom is a physical layer that is controlled; on top of it is a logical layer that is free; and on top of both is a content layer that mixes free and controlled.

This complexity builds a commons. And this commons has been the location of some of the most extraordinary innovation that we have seen. Not innovation in just the dotcom sense, but innovation in the ways humans interact, innovation in the ways that culture is spread, and most importantly, innovation in the ways in which culture gets built. The innovation of the Internet-built into its architecture-is an innovation in the ways in which culture gets made. Let the dotcom era flame out. It won't matter to this innovation one bit. The crucial feature of this new space is the low cost of digital creation, and the low costs of delivering what gets created.

\section{Closing COMMUNiCATION SYSTEMS}

Now I have dissected this commons into these layers to help us see more precisely just how it will be enclosed. So far my message has been fairly bright; but my brand is pessimism, and so we need a good dollop of darkness.

And the fact is, darkness here is not hard to find. For though we have just begun to see how this freedom functions, we are quickly coming to see how this freedom will be removed. These layers mixing 
the free and the controlled are quickly becoming layers that simply mix different kinds of control.

We are in the midst of a process by which, through law and through technology, these features of this initial architecture are changing. Because we believe "the whole world is best managed when divided among private owners," $"$ we are changing the architecture of the Net to enable it to be divided and controlled; because we believe "the whole world is best managed when divided among private owners," we are expanding and reinforcing control over content through IP law; because we believe, as our ideology says, we are remaking the Internet to fit this ideology. Without even pausing to understand it; without taking a moment to see how it might actually work; we are mapmakers who, upon finding that the city doesn't quite fit our map — an extra building here, and river we didn't expect there-proceed to remake the city to make sure it fits the map.

Consider these remakings.

I said that the commons that fuels innovation is the commons that exists at the logical layer of the Net. This is the commons constituted by the principle of end-to-end; it is the commons that gets built by a set of protocols that don't discriminate. It is the neutral platform upon which innovation happens. And this neutrality is neutrality built into the code.

But this code is not given. The code governing a network is not fixed. The code that governs at one time could be replaced by a different code later on. And more importantly, there is nothing that forces people who connect to the Net to obey the neutrality of the net. There is no brand called "the Internet" that carries with it a set of assumptions about openness and balance; there is instead a basic set of protocols that anyone is free to supplement with protocols added on top.

Anyone is free to change it, and some important people are changing it. One such example is the providers of broadband services.

As the Internet moves from the telephones (from modems and 28.8 or $56 \mathrm{k}$ connections) to broadband, to fast, always-on connections, the physical layer across which the Internet travels is different.

12. Rose, supra note 1 , at 712 . 
The dominant technology today for serving this broadband content is cable.

Now, as cable converts to make itself open to the Internet, it is modifying the architecture of the Internet in an important way. While the essence of the commons of the Internet was neutrality and simplicity, the essence of what the broadband cable Internet will be is the power to discriminate in content and services. The aim of this form of Internet access will not be openness and neutral platforms; the aim of this form of Internet access will be control over the content that gets played.

For example: Cable companies make a great deal of money streaming video to television sets. That is the core of their legacy monopoly power. Some think it would be useful to stream video to computers. Cable companies were not eager to see this form of competition. So they imposed rules on broadband users-no more than ten minutes of streaming video could be contracted for at any time. ${ }^{13}$ When they were smart, they said they were worried about congestion. But when they were honest they said something different. Daniel Somers, of AT\&T, said that the company didn't spend fifty-six billion dollars on a cable network "to have the blood sucked out of our vein[s]." ${ }^{, 14}$

Broadband providers will insist that this control is their rightthat nothing should interfere with their right to layer onto the free logical layer a system of control. And a budding line of First Amendment doctrine (embraced and pushed by judges in the United States Court of Appeals for the District of Columbia Circuit) strongly supports this claim. ${ }^{15}$

These cases are Blade-Runner-esque. Remember that one of the million amazing puzzles in that extraordinary film is the slow recognition that these machines are human. Well here too, with the cable system, it is the increasing recognition that these systems to deliver electricity are in fact First Amendment speakers. Wires plus a certain logic produce "the press"; and then into the mix comes the District of

13. LESSIG, supra note 6, at 156-59.

14. David Lieberman, Media Giants' Net Change: Major Companies Establish Strong Foothold Online, USA TODAY, Dec. 14, 1999, at B2.

15. See Fox Television Stations, Inc., v. Federal Communications Commission and United States, 280 F.3d 1027, 1045-47 (D.C. Cir. 2001) (accepting the argument that cable stations are speakers). 
Columbia Circuit eager to bestow on this press long standing First Amendment power.

And hence we should expect, as the Internet moves to this broadband, that the rules governing the providers will be different. Unlike the telephone company, these providers will be allowed to discriminate; and discriminate, they will; and, when they do, this open feature of the Internet commons will be removed. Enclosed. Chopped up and sold off. With the consequence that innovation here will be different.

\section{CONTROLLING COMMUNICATION SYSTEMS}

That's a change at the logical layer-or more precisely, a set of controls that gets layered on at the logical layer. But the changes are not just here. More dramatic, less justified, but more likely are changes at the content layer. These are the changes most remarked upon here. And hence these will be a bit easier to describe.

The content I want to focus on here is controlled by copyright law. Ideas, or, more properly, inventions, get controlled by patent law; context, or the expression of ideas, is regulated by copyright.

Copyright law has changed. Changed. In the sense that becoming an oak tree is a change of the acorn, modern copyright law is a change over the copyright law that was.

When the United States was formed, the Constitution gave Congress the power to grant "authors" exclusive rights for their "writings" for a "limited time" to-as the Constitution expressly states"promote progress." The Promote Progress Clause is unique in the Constitution's enumeration of powers-every other clause leaves the purpose unspecified; only this clause specifies for what the power may be used.

The first federal copyright statute was enacted in $1790 .{ }^{17}$ That Act regulated the "printing" and "vending" of "map[s], chart[s] and... book[s]" for an initial term of fourteen years. ${ }^{18}$ While in principle anyone could violate the exclusive right to vend, in 1790, there were only 127 printing establishments in the United States. ${ }^{19}$ Copyright was

\footnotetext{
16. U.S. CONST. art. I, $\S 8$.

17. Act of May 31, 1790, ch. 15, 1 Stat. 124 (repealed 1802).

18. Id. $\S 1,1$ Stat. at 124.

19. LESSIG, supra note 6, at 106.
} 
not automatic; registration was required; most of the early registrations were for scientific or instructional texts. Between 1790 and 1799, 13,000 titles were published in America, but only 556 copyright registrations were filed. ${ }^{20}$ More than $95 \%$ of published work therefore fell immediately into the public domain-including, of course, $100 \%$ of foreign work. Our outrage at Chinese piracy notwithstanding, we should not forget that until 1891, foreign copyrights were not protected in America. ${ }^{21} \mathrm{We}$ were born, in other words, a pirate nation. ${ }^{22}$

Thus the law was slight, as was the actual scope of protection. Copyright did not protect derivative works; you could translate or adapt or abridge or set to song copyrighted works, without the permission of the author. The monopoly rights that the 1790 statute granted were essentially protections against pirate presses. The target of the regulation was the press that would take an American author's book and simply reproduce it without compensation to the original author. These pirate presses were to focus their energy on stealing from the British and French; Americans were to be exempted from the pirate trade.

Copyright has changed. It no longer is limited to maps, charts and books. It now touches practically any creative work reduced to a tangible form. It protects music, and performances, and architecture, and certain design. It protects machines written in words-we call that software-and words written on machines-we call that the Internet.

And it no longer protects these creative acts for an initial term of fourteen years. It protects these creative works for the life of the author plus seventy years ${ }^{23}$ - which means, for example, in the case of Irving Berlin, a term that exceeds 140 years. It protects this work not contingently; not, that is, upon registration. It protects it, and all creative work, automatically-for a term that does not have to be renewed, for a life that exceeds the author's.

20. Id.

21. Act of Mar. 3, 1891, ch. 565, $\S 13,26$ Stat. 1106, 1110.

22. I discussed the history of copyright law in the Melville V. Nimmer Memorial Lecture at UCLA on March 1, 2001. For the full text of this lecture, see Lawrence Lessig, Copyright's First Amendment, 48 UCLA L. REV. 1057 (2001).

23. 17 U.S.C. $\$ 302(2000)$. 
And it protects not just against pirate publishers. The scope of copyright now protects an extraordinarily broad derivative right. The right to translate, with some works, the right to perform, the right to adapt to a play, or make a movie-all these are rights that are now included within the originally sparse "exclusive right" that the original copyright act granted.

And finally, because it doesn't protect only against pirate publishers, because in 1909 the statute shifted its terms, to speak of "copies" and not printing, ${ }^{24}$ and because the technology of copying has now exploded to cover just about anything anyone does with a computer, the reach of this regulation is no longer the 127 publishers that existed in 1790 . The reach of this regulation on the right to speak extends to the 127 million Americans who today use computers. This tiny regulation of a tiny proportion of the extraordinary range of creative work in 1790 has morphed into this massive regulation of everyone who has any connection to the most trivial of creative authorship.

No doubt, and I certainly believe, much of the expanse in copyright over the past two hundred years was completely justified under a proper reading of the balance the framers meant to strike. Though they didn't protect music, it would be wrong for us not to protect music. I realize there are those on the other side-those who note that while our system of protection has produced Britney Spears and Madonna, the framers' system of nonprotection produced Beethoven, and maybe that means the framers were on to something-but I'm not on the side of free music if free music means artists don't get paid. In my view, the issue is not whether artists get paid; the issue is how. Congress has been correct in its efforts to extend rights to assure artists get paid, so as to assure a sufficient incentive to produce art.

Thus we should notice this expansion not so much to oppose it, but to recognize its inertia. Control is our direction, and our velocity has been set. Something big will have to happen if this inertia is to be checked. Something significant in the culture must block it if the inevitable it promises - the inevitable of perfect control-is to be avoided.

24. Act of Mar. 4, 1909, Pub. L. No. 60-349, § 1, 35 Stat. 1075, 1075 (codified as amended at 17 U.S.C. $\S 101(2000))$. 
Instead, something big has happened that has accelerated the push to perfect control. And paradoxically, that something big that will push copyright to perfect control is this architecture of freedom we call the Internet.

For before the Internet, in my humble view, there was little reason to worry about the emergence of control. I realize this is a controversial view here. Professor Lange was lamenting the commons long before any of us had linked with html. ${ }^{25}$ Long before the name Hilary Rosen became a chatroom slur, ${ }^{26}$ Professor Lange was building outrage at the tendency of IP lawyers to overreach. Indeed, in a passage from his Reclaiming the Public Domain, Professor Lange captures the essence of where we are now, with a style and authority that reminds one of Charles Black's account of Brown v. Board of Education. $^{27}$ Professor Lange tells us what we all know, but reminds us how the legal system makes it impossible to say what we know:

The defendants, of course, were obliged to take each of these claims seriously and to respond to them with earnest denials rooted firmly in law. But I am free to recognize them for the utter nonsense they are. Legitimate works deserve protection from real threats. But claims of this kind are so extravagant in relation to the reality from which in theory they ought to spring that one is tempted not merely to dismiss them as nonsense, but to suggest in addition that one day one of them ought to be made the subject of a serious counterclaim for punitive damages rooted in some sort of tort designed expressly for the purpose, perhaps to be termed "unconscionable overreaching." 28

Thus the practice we can't escape seeing today is, of course, a practice that others have noticed from time immemorial. The extremes of the Recording Industry Association of America (RIAA) were not invented by the RIAA. Professor Lange retells in the same article the extraordinary story of Warner Brothers threatening the Marx Brothers when Groucho was considering a production to be titled "A Night in Casablanca." ${ }^{29}$ For, of course, Warner Brothers be-

25. Lange, supra note 2.

26. LESSIG, supra note 6, at 200. As president of RIAA, Hilary Rosen declared that the industry's objective was to limit venture capital such that content available on the Internet had been approved by the industry. $I d$.

27. Appellants' Reply Brief, Brown v. Bd. of Educ., 347 U.S. 483 (1954).

28. Lange, supra note 2, at 166.

29. Id. at $172-73$. 
lieved it owned the name "Casablanca," which inspired Groucho to respond that he believed, since the Marx Brothers predated Warner Brothers, that he owned the word "Brothers" and that Warner had better back off. ${ }^{30}$

Yet there is a difference in these blusterings of lawyers today, and the difference is in the code. Not in the code architected by East Coast coders-legislators in Washington-but in the code architected by West Coast coders - the code of software and the control built into it. The difference is that now, these systems of control can be built into an architecture that must recognize them; the encodings and control, as Professor Boyle puts it, following Michael Foucault, get inscribed into the wires. ${ }^{31}$ And, when this discipline gets encoded into the wires, then this discipline is bizarrely more important than when it is simply the overreaching of lawyers. Now the over-reaching of an ebook that says, "You can read this on a Windows machine, but not on a Macintosh," is something more than bluster. It is a set of controls with the power of mathematics behind it-we call that encryptionand now these controls have the power of law to defend them-we call that the Digital Millennium Copyright Act. ${ }^{32}$

This layer of control is new in the game; this layer is exploding and the law is expanding to back it up. And hence now, just at the moment that technology could enable a billion lifelike innovations, a billion iMacs crafting movies by remixing culture from the past, just at the moment when the technology could make real the idea captured in an Apple commercial-rip, mix, and burn, after all, as the commercial ends, it is your music - the technology is taking that freedom away. The very same iMac which Apple tries to sell with this picture of freedom-rip mix and burn-is encoded with software to handle DVDs that does not enable the ripping, mixing, or burning of Hollywood's movies. Try to rip, mix, and burn that stuff and the system will quickly crash. Control of that content has been encoded; and this system of "freedom" has been encoded to respect that control.

30. Id. at 173 .

31. See James D. Boyle, Foucault in Cyberspace: Surveillance, Sovereignty, and Hardwire Censors, 66 U. CIN. L. REV. 177, 201-02 (1997) (describing how technological controls embedded in information could dictate information flow on the Internet); see also Albert Kovacs, Note, Quieting the Virtual Prison Riot: Why the Internet's Spirit of "Sharing" Must Be Broken, 51 DUKE L.J. 753, 769-85 (2001) (applying Foucault's analysis to music sharing on the Internet).

32. Pub. L. No. 105-304, 112 Stat. 2860 (1998) (codified at 17 U.S.C. $\S \S 1201-05,1301-32$ (2000)). 
This is the conflict between two pictures of the future. One, the future of imperfect control at the content layer-music that gets ripped, mixed, and burned; the other, the future of perfect controlof DVDs that get ripped, mixed, and burned only as Jack Valenti, President and CEO of the Motion Picture Association of America, allows. And my bet is with the future of perfect control. For as well as an infrastructure that can have control layered onto it-the Internet-and as well as code that can build control into content-copyright management regimes-and as well as law that will back up the control that gets built into content that gets served across this infrastructure - the DMCA - the more important reason to bet on a future of control is culture. It isn't the West Coast code that will matter most; it isn't the East Coast code that will make the difference; the real issue is the culture, and its code; the real power is in a set of ideas that is still taken for granted.

\section{CONCLUSIONS}

For this is what I spoke of at the start, and it is this that will define the end. Ideas that are taken for granted; that are unquestioned in this culture; that to question, would render you an alien; these ideas are the ideas that will make control the future.

For these ideas take for granted the property in intellectual property. These ideas have lost the distinction that our framers made clear-by speaking as they did, not of intellectual property, but of monopolies and exclusive rights. That's what a copyright or patent is-a government backed monopoly, not over a rivalrous or scarce resource like land or apples or heated homes, but over a nonrivalrous resource that the Enlightenment taught us should be shared among more than the Church. IP is not P, but this truth is lost on us.

And so deeply is it lost that we don't even notice the irony it produces. We speak of a commons as if it is only a tragedy; we recall the public domain as if it were simply an echo from some romantic past; we embrace, as Professor Rose says, the idea that the whole world is best managed when divided among private owners, ${ }^{33}$ and we proceed to divide the world among private owners. Most Americans agree with the Walt Disney Corporation that Mickey Mouse is Disney's now and forever; they don't even notice the irony then when

33. Rose, supra note 1 , at 712 . 
Disney can make millions off of Victor Hugo's creation, the Hunch Back of Notre Dame, or Sergei Prokofiev or Pocahontas. So invisible is public domain that we don't even see it when it is everywhere around; so invisible is the idea that the free might matter to creativity, that when it is enclosed, we are convinced this is progress.

Our future is this: the Free Speech Clause of the First Amendment will be read to entitle those who own the wires to change the logical layer and make it owned as well; the free competition principle of the Sherman Act will be read (by the same Circuit Court of Appeals, we might notice) to entitle the owner of the platform that most affects this logical layer (that one company whose name I have not uttered) to code that platform to discriminate as it wants; and the free culture that we have seen flourish in this commons built by the Internet will be captured and controlled again by those who control most of the content, and by those who succeed in Congress in expanding their control from the imperfect to the perfect. And this future of control will get built by an idea: that property is good, so more property is better. It will get sanctioned by a culture that has forgotten distinction, and that is so blinded by what it has forgotten that it does not even notice when the most extraordinary innovation that our culture has seen is built not on an architecture of perfect freedom; not in a world where every layer is in the commons, but also not on an architecture where control is the rule. Not, in other words, on an architecture where every layer is owned; but instead, on an architecture that mixes freedom and control, that built property within a commons, and that got its life from this mix of property and the commons.

At every layer, we are displacing the free with control, and the reasons for this displacing are not hard to see. This architecture of innovation that we call the Internet threatens the systems of control that thrived before there was such a thing as the Internet. And those whose interests are most threatened by this innovation have rallied to undermine what is special about it.

This is nothing new with the Internet. In his extraordinary work, The Prince, Niccolo Machiavelli had this to say about innovation:

Such an innovator has as enemies all the people who were doing well under the old order, and only halfhearted defenders in those who hope to profit from the new. This halfheartedness derives partly from fear of opponents who have the law on their side, and partly 
from human skepticism, since men don't really believe in anything new till they have solid experience of it. ${ }^{34}$

We allow these changes; they don't just happen. We stand back as they occur; they don't happen in the night. We let them occur because most of us believe they should; that control is good, better control is better, and that these systems of control are ways to make sure the better comes from the good.

It is an attitude and blindness and a pathetic resignation that permits this change. So enamored we are with the invisible hand, so convinced we are of the genius of property, so blind we are to what makes innovation possible, that we allow the undoing of the most significant chance for something different than we have ever seen.

When I talk about this loss in other places, most don't really get it. They clap politely, and then they ask, What is innovation? You haven't defined the good in innovation. What do we lose when control is the norm? What really is to be gained from freedom?

These are people who can't imagine a world where culture is anything else but served on a platter. These are people for whom the idea of cultural production is only ever associated with the state (as in China) or the corporation (as in a production department). These are people who can't imagine culture being reproduced and recreated by individuals, or by small groups working together, with a technology that enables a remaking of culture.

These are people who have not seen the films of Professor Lange's students; who have not read the politics in Professor Boyle's writings; who have not begun to understand the lesson of the harm to science taught by Professor Reichman.

These are people who have not been to Duke. And so I come to Duke to do little more than report on a war we are losing. Of a culture that can't see the potential that this architecture presents. Of a politics that scorns anyone who questions that übervision of perfect control.

34. Niccolò Machiavelli, The Prince 17 (Robert M. Adams trans., W.W. Norton \& Co., Inc. ed., 1992) (1513). 
The irony astounds. We win the cold war against state control so as to reentrench this system of control in the name of the market. We fight battles in the name of free speech, only to have those tools turned over to the arsenal of those who would control speech. We defend the ideal of property, and then confuse its limits, and extend its reach to a space none of our founders would ever have imagined.

We move through this moment of an architecture of innovation, to once again an architecture of control. Without notice; without resistance; without a question.

This, you may notice, is a contradiction in our tradition. You might be tempted to then repeat my favorite line from Professor Boyle's book: "I have nothing against contradictions, some of my best friends are contradictions ....",

This is a contradiction we should be against. Yet, we, Americans, are not.

35. BOYLE, supra note 3, at 169. 